\title{
Cytomorphological Spectrum of Granulomatous Mastitis: A Study of 33 Cases
}

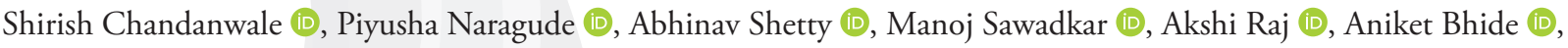 \\ Madhuri Singh (1) \\ Department of Pathology, Dr. D. Y. Patil Medical College, Hospital \& Research Centre, Pimpri Pune, India
}

\begin{abstract}
Objective: Granulomatous mastitis is an uncommon benign breast disease. Varied aetiologies such as tuberculosis, foreign body reactions, sarcoidosis, fungal and parasitic infections and autoimmunity have been suggested. Pre-operative definitive diagnosis is essential for proper treatment. In developing countries like India, fine needle aspiration is still widely used as a reliable technique for preoperative evaluation of palpable breast lumps. The objective of this study is to study the cytomorphological features of different forms of granulomatous mastitis and correlate with other clinical findings including histological features.

Materials and Methods: A total of 33 cases of granulomatous mastitis were reviewed. The patients underwent fine needle aspiration. Cytomorphological features were studied in detail and correlated with histopathological features and other clinical findings.

Results: All the 33 patients showed varied cytomorphological features which included epithelioid cells/granuloma with lymphocytes/plasma cells/ polymorphs with or without necrosis/caseous necrosis and with or without giant cells. Ziehl Nelson stain showed acid fast bacilli in 13 smears. Out of 17 cases, the eight cases showed positive acid fast bacilli culture. Fungal stain such as Grocott- Gommeri Methane amine did not show fungi. Based on cytomorphological features in aspiration smears, they were grouped into 4 Groups. A total of 27 breast lesions were diagnosed as tuberculous mastitis, the four lesions were diagnosed as idiopathic granulomatous lobular mastitis and two lesions were diagnosed as foreign body granulomatous mastitis. Grocott- Gommeri Methane amine did not showed fungi. Based on cytomorphological features in aspiration smears, they were grouped into 4 Groups. A total of 27 breast lesions were diagnosed as tuberculous mastitis, the four lesions were diagnosed as idiopathic granulomatous lobular mastitis and two lesions were diagnosed as foreign body granulomatous mastitis.

Conclusion: Epithelioid granulomas with caseous necrosis with or without acid fast bacilli in cytology smears are diagnostic of tuberculosis. Cytology smears showing epithelioid granulomas with predominant polymorphs without necrosis and acid fast bacilli, a diagnosis of idiopathic granulomatous lobular mastitis must be considered. Histopathological examination is essential for definitive diagnosis in these cases.
\end{abstract}

Keywords: Epithelioid cells, lobular mastitis, mastitis, needle aspiration, tuberculosis

Cite this articles as: Chandanwale S, Naragude P, Shetty A, Sawadkar M, Raj A, Bhide A, et al. Cytomorphological Spectrum of Granulomatous Mastitis: A Study of 33 Cases. Eur J Breast Health 2020; 16(2): 146-151.

\section{Introduction}

Granulomatous mastitis (GM) is an uncommon benign breast disease. Two defined forms of GM have been identified. 1)Idiopathic granulomatous lobular mastitis (IGLM). 2)GM with specific aetiology. Many aetiologies such as tuberculosis, foreign body reactions, sarcoidosis, mycotic and parasitic infection and autoimmunity have been suggested $(1,2)$. Some of the forms clinically simulate carcinoma. Extra-pulmonary tuberculosis is on the rise world over. Tuberculous mastitis is relatively a rare disease with reported incidence varying from 3-4.5\% in developing countries like India. The radiological features are non-specific. IGLM is a rare chronic inflammatory disease of unknown aetiology. It has high rate of recurrence and develop complications such as sinus formation and skin ulceration. To avoid unnecessary surgery definitive diagnosis of various forms of GM is warranted (2-4). In developing countries, fine needle aspiration (FNA) is widely accepted as a reliable technique for preoperative evaluation of palpable breast lumps $(5,6)$. The aim of this study is to evaluate the cytomorphological features of different forms of granulomatous mastitis and correlate with other clinical findings including histological features.

\section{Materials and Methods}

This is a retrospective study over the period of five years. A total of 33 cases of mastitis were included in the study. Inclusion criteria: Benign breast lesions showing epithelioid cells in FNA smears. Exclusion criteria: Known cases of tuberculous mastitis on treatment. The 
study included 33 cases of GM diagnosed on FNA. Medical records of these cases were retrieved and all the clinical details were noted. Cytomorphological, histological features and other clinical findings were reviewed and analysed. All the patients underwent FNA after prior written consent. Aspiration was done with aseptic precautions using 22 -gauge needle connected to a $10 \mathrm{ml}$ syringe with FNA gun. Smears were stained using Leishman and Haematoxylin and Eosin ( $\mathrm{H}$ and $\mathrm{E})$ stains. Remaining smears were stained with Ziehl and Nelson (Z.N.) and Grocott-Gomorimethanamine (GMS) stains for the presence of acid fast bacilli (AFB) and fungi, respectively. Cases in which aspirate was available or pus, was sent for AFB culture.

FNA smears and histopathology slides were studied independently by two pathologists. FNA smears were looked for epithelioid cells/granulomas, lymphocytes, polymorphonuclear leukocytes, plasma cells, eosinophils, giant cells, necrosis/caseous necrosis, AFB, fungal hyphae, and other cytological findings. Detailed clinical presentation including age, sex, marital status, number of pregnancies and last pregnancy, history of lactation, use of contraceptives, nicotine abuse, presence of systemic disease, cough, fever, weight loss and any family history of tuberculosis were noted. Ultrasonography and mammography finding were noted in all cases.

Cases in which surgical/biopsy specimens were received for histopathological examination, were formalin fixed and paraffin processed. 3-4 microns thick sections were stained with routine $\mathrm{H}$ and $\mathrm{E}, \mathrm{Z} \mathrm{N}$ and GMS stains. FNA features were correlated with clinical findings, radiological findings and histopathological findings. Culture for AFB was done in 17 cases by using Lowenstein Jenson (LJ) media. Subsequently findings of additional investigations such as tuberculin test, $\mathrm{X}$ ray and computed tomography $(\mathrm{CT})$ of the chest were available in all patients. Statistical data was analysed and tabulated.

\section{Results}

In the series of 33 cases of GM, 32 were females and one was male. The patients age ranged from 19 to 75 years with mean age of 44 years. Maximum patients $(n=12)$ were in the age group of $31-40$ years. Table 1 show detailed age and sex distribution of 33 patients. Right breast $(n=23)$ was commonly involved than left breast $(\mathrm{n}=10)$.

The diagnosis of GM was made by presence of epithelioid granulomas or scattered epithelioid cells along with other inflammatory cells with or without giant cells in FNA smears. Based on clinical findings and morphology of granuloma with other inflammatory cells, giant cells and presence or absence of AFB in FNA smears, AFB culture examination and histomorphological features, aetiology of GM was specified. Out of 33 cases of, maximum $(n=27)$ cases were diagnosed as tuberculous mastitis (TM), followed by IGLM ( $n=4)$ and foreign body granulomatous mastitis $(n=2)$. Right breast was involved in 23 cases and left breast was involved in 10 cases. Out of 27 patients of TB mastitis, maximum $(n=21)$ patients presented with nodular pattern of growth. Table 2 show detailed age sex group and clinical findings in various forms of granulomatous mastitis.

Ultrasonography and mammography were done in all cases. Commonest ultrasonography finding $(\mathrm{n}=25)$ was heterogeneous hypoechoic lesion. Mammography showed focal asymmetric density in 29 cases. All the patients were seronegative for human immunodeficiency virus (HIV).

Cytomorphological features were studied in detail and they were categorised into four groups (Table 3).
Table 1. Age and sex distribution of granulomatous mastitis

\begin{tabular}{lccc|} 
Age (Years) & Male & Female & Total \\
$0-20$ & 0 & 3 & 3 \\
$21-30$ & 0 & 7 & 7 \\
$31-40$ & 1 & 11 & 12 \\
$41-50$ & 0 & 4 & 4 \\
$51-60$ & 0 & 3 & 3 \\
$61-70$ & 0 & 2 & 2 \\
70 above & 0 & 2 & 2 \\
Total & 1 & 32 & 33 \\
\hline
\end{tabular}

Table 2. Age, sex and clinical features in different types of granulomatous mastitis

\begin{tabular}{|c|c|c|c|c|}
\hline \multicolumn{2}{|c|}{ Age group } & $\begin{array}{l}\text { TB Mastitis } \\
(n=27)\end{array}$ & $\begin{array}{l}\text { Foreign body } \\
\text { Granulomatous } \\
\text { Mastitis ( } n=2)\end{array}$ & $\begin{array}{l}\text { IGLM } \\
(n=4)\end{array}$ \\
\hline \multicolumn{2}{|c|}{$0-20$} & 3 & 0 & 0 \\
\hline \multicolumn{2}{|c|}{$21-30$} & 3 & 0 & 4 \\
\hline \multicolumn{2}{|c|}{$31-40$} & 12 & 0 & 0 \\
\hline \multicolumn{2}{|c|}{$41-50$} & 2 & 2 & 0 \\
\hline \multicolumn{2}{|c|}{$51-60$} & 3 & 0 & 0 \\
\hline \multicolumn{2}{|c|}{$61-70$} & 2 & 0 & 0 \\
\hline \multicolumn{2}{|l|}{$>70$} & 2 & 0 & 0 \\
\hline \multicolumn{2}{|c|}{ Total } & 27 & 2 & 4 \\
\hline & M & 1 & 0 & 0 \\
\hline & $\mathrm{F}$ & 26 & 2 & 4 \\
\hline \multicolumn{5}{|c|}{ Clinical Findings } \\
\hline \multicolumn{2}{|c|}{ Nodular Pattern } & 20 & 0 & 2 \\
\hline \multicolumn{2}{|c|}{ Sclerosing Pattern } & 3 & 2 & 2 \\
\hline \multicolumn{2}{|c|}{ Disseminated Pattern } & 4 & 0 & 0 \\
\hline \multicolumn{2}{|c|}{ Mastalgia } & 3 & 2 & 2 \\
\hline \multicolumn{2}{|c|}{ Axillary lymphadenopathy } & 3 & 0 & 0 \\
\hline \multicolumn{2}{|c|}{$\begin{array}{l}\text { H/o lactation since last } \\
6 \text { months }\end{array}$} & 1 & 1 & 3 \\
\hline \multicolumn{3}{|c|}{ Family history of tuberculosis 2} & 0 & 0 \\
\hline
\end{tabular}

Group 1 ( $n=2)$ showed epithelioid cells/granuloma mixed with lymphocytes and plasma cells without necrosis with or without giant cells (Figure 1a and b).

Group 2 ( $n=22)$ showed epithelioid cells/granuloma with necrosis/caseous mixed with lymphocytes and plasma cells with or without giant cells (Figure 1c and b). 
Table 3. Pattern of granulomatous inflammation on FNA smears of 33 granulomatous patients

\begin{tabular}{|llcc} 
Pattern & Cytomorphology & N (number) & \% \\
\hline Group 1 & $\begin{array}{l}\text { Epithelioid granulomas mixed with lymphocytes, plasma cells without necrosis with or } \\
\text { without giant cells }\end{array}$ & 2 \\
Group 2 & $\begin{array}{l}\text { Epithelioid granulomas mixed with lymphocytes, plasma cells with necrosis/ caseous } \\
\text { with or without giant cells }\end{array}$ & 22 & 66.06 \\
Group 3 & $\begin{array}{l}\text { Suppurative necrosis with epithelioid granulomas / epithelioid cells } \\
\text { Eroup } 4\end{array}$ & 6 & 3.18 \\
without giant cells & 3.09
\end{tabular}
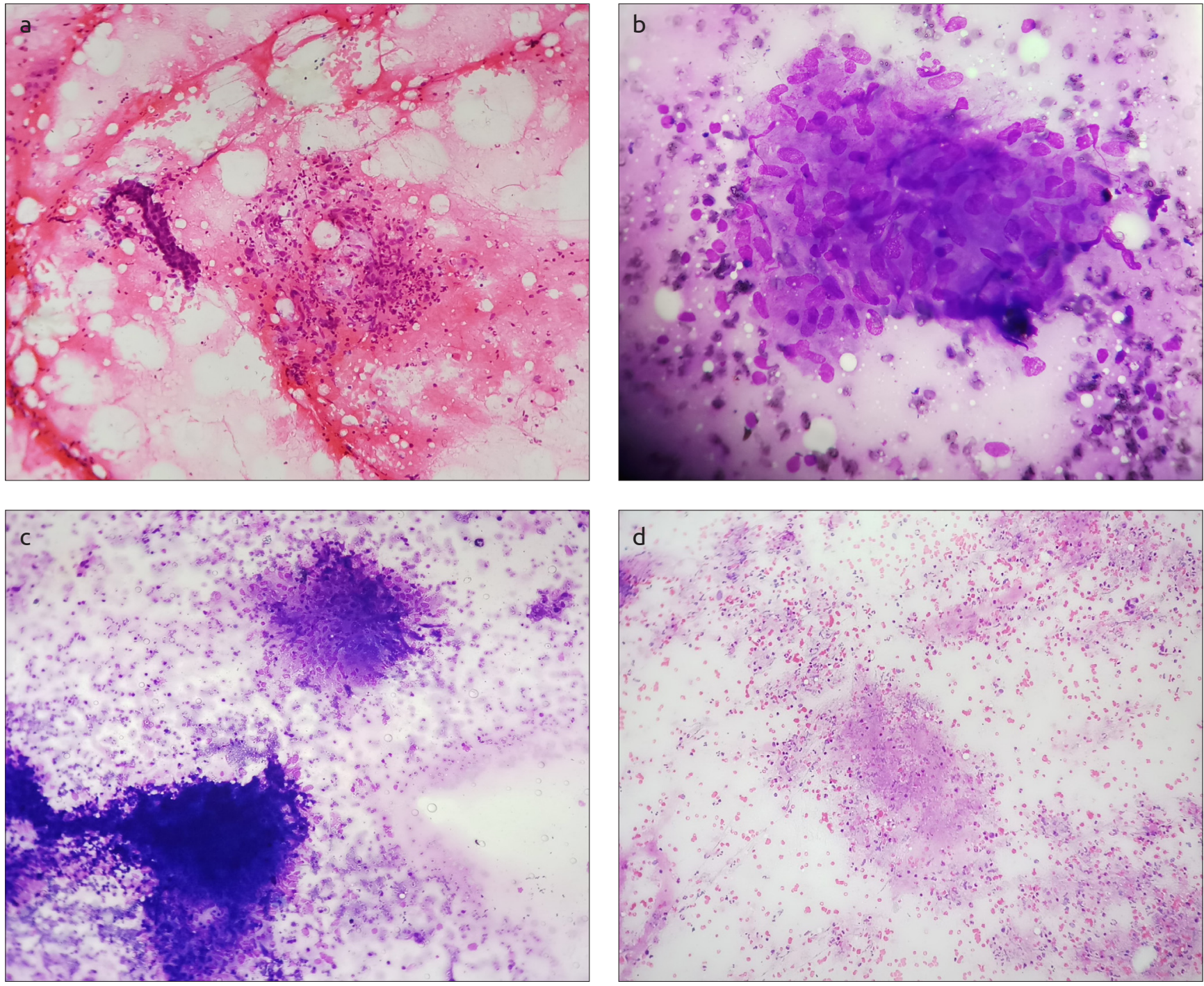

Figure 1. a-d. (a) Smear show epithelioid granuloma, and ductal epithelial cells. (a) (Haematoxylin and Eosin x100). (b): Smear show epithelioid granuloma (Leishman stain $\times 400$ ). (c): Smear show epithelioid granuloma with areas of necrosis (Leishman stain x100). (d): Smear show caseous necrosis (Leishman stain $\times 100)$

Group 3 ( $n=6$ ) showed supurative necrosis with epithelioid cells/granuloma (Figure 2a and b).

Group $4(\mathrm{n}=3)$ showed epithelioid cells/ granuloma mixed with polymorphonuclear leukocytes without necrosis and with or without giant
In addition, three cases showed few scattered large atypical epithelial cells (Figure 3a).

$\mathrm{ZN}$ stain was done in all FNA smears and AFB were seen in 13 smears. Out of 17 cases in which AFB culture was done, 8 cases showed positive AFB culture. Fungal stain was done in 7 cases and none of the cases showed fungi. 

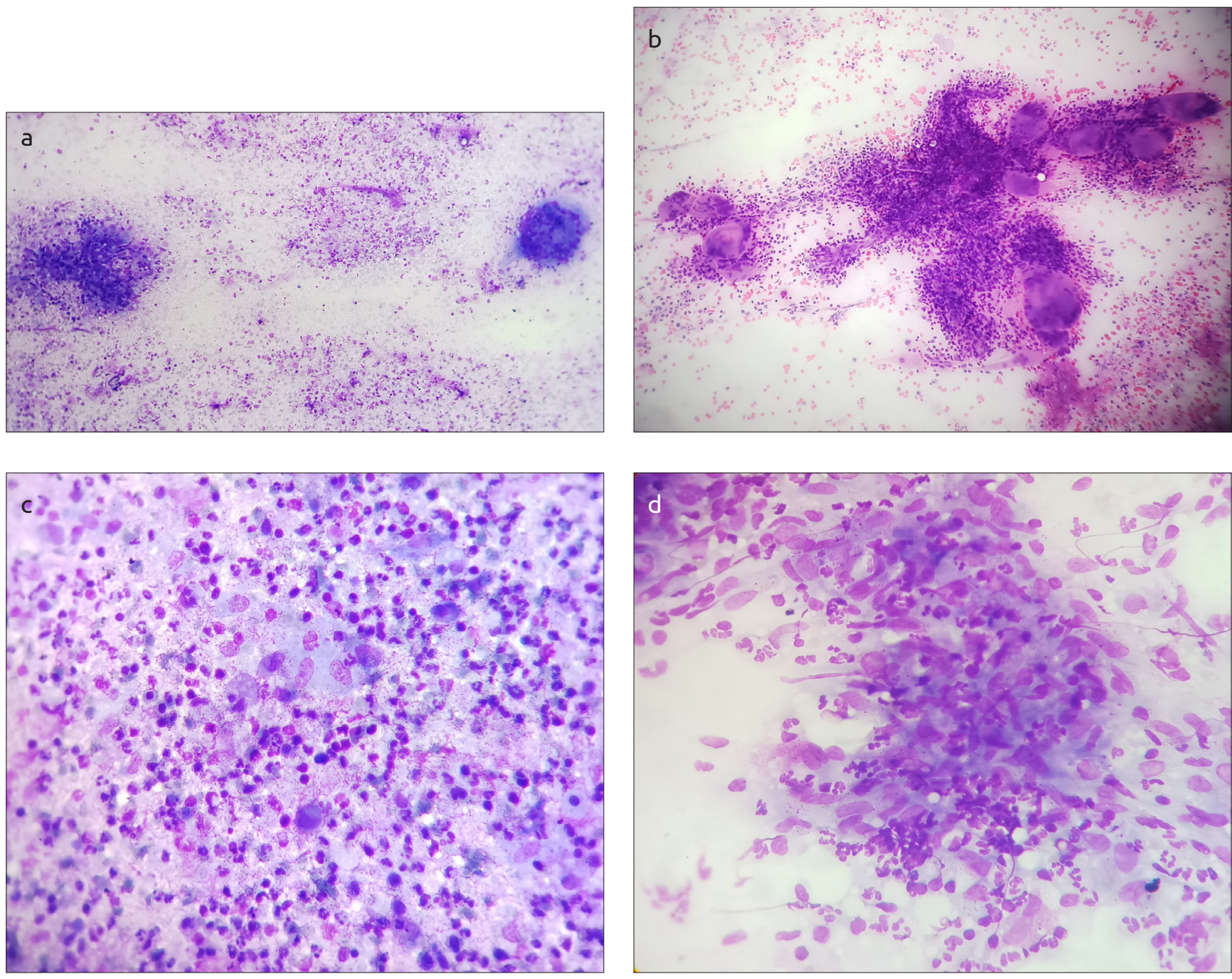

Figure 2. a-d. (a) Smear show epithelioid granuloma, giant cell and suppurative background (Leishman stain x100). (b): Smears show many epithelioid granulomas, giant cells and polymorphs (Leishman stain x400). (c): Smears show many epithelioid granulomas, giant cells, polymorphs and few lymphocytes (Leishman stain x400). (d): Smears show many epithelioid granulomas mixed with polymorphs (Leishman stain $\times 400)$

The definitive diagnosis of tuberculous mastitis was based on FNA features of epithelioid cells/granuloma with caseous necrosis with or without AFB or AFB culture positivity. The cases in which necrosis or AFB were not seen in FNA smears, the diagnosis Tb mastitis was established by AFB culture or histopathological examination.

Out of 27 cases of $\mathrm{Tb}$ mastitis, histopathological examination was done in six cases. out of 6 cases, two cases in which FNA smears showed Group1 pattern, biopsy showed epithelioid granulomas mixed with lymphocytes, occasional Langhans giant cell and caseous necrosis. $\mathrm{ZN}$ stain in both cases showed AFB and diagnosis of Tb mastitis was established. The four cases out of which FNA smears in three cases of Group 4 pattern and one case of Group 3 pattern did not show AFB or fungi on special stains. Biopsy in these cases were received for histopathological examination showed inflammatory infiltrate of polymorphs, lymphocytes and epithelioid granulomas and giant cells confined predominantly to lobules. Stroma showed focal scanty lympho-plasmocytic inflammatory infiltrate. There was no caseous necrosis (Figure 3b). Special stains did not reveal AFB and fungi. In all these four cases, diagnosis of IGLM was made. None of the patients showed evidence of pulmonary tuberculosis on $\mathrm{X}$ ray and $\mathrm{CT}$ of the chest.
Diagnosis of foreign body granulomatous mastitis based on strong clinical history, FNA features of granulomas, giant cells without AFB in smears and negative AFB culture. The diagnosis was confirmed by histopathological examination.

\section{Discussion and Conclusion}

In 1972, Kessler and Wolloch emphasized in their study that granulomatous mastitis is a rare condition and its aetiology is not known (7). Subsequently, Jayram G from India reported cases of granulomatous mastitis of tubercular aetiology (8). Other aetiologies such as foreign body reactions, sarcoidosis, fungal and parasitic infections and autoimmunity have been suggested $(1,2)$. Though granulomatous mastitis can occur at any age, it is more common in women of child bearing age and commonly occur in $3^{\text {rd }}$ and $4^{\text {th }}$ decade $(9,10)$. Males are rarely affected and it has been occasionally reported in elderly patients (2). In contrast in our study, GM $(\mathrm{n}=19)$ more commonly occurred in $2^{\text {nd }} 3^{\text {rd }}$ decade (Table 1).

Breast is a uncommon site for tuberculosis even in countries like India, where tuberculosis is rampant. It affects commonly women in the reproductive age group of 21 to 40 years (11-13). In our study, a substan- 

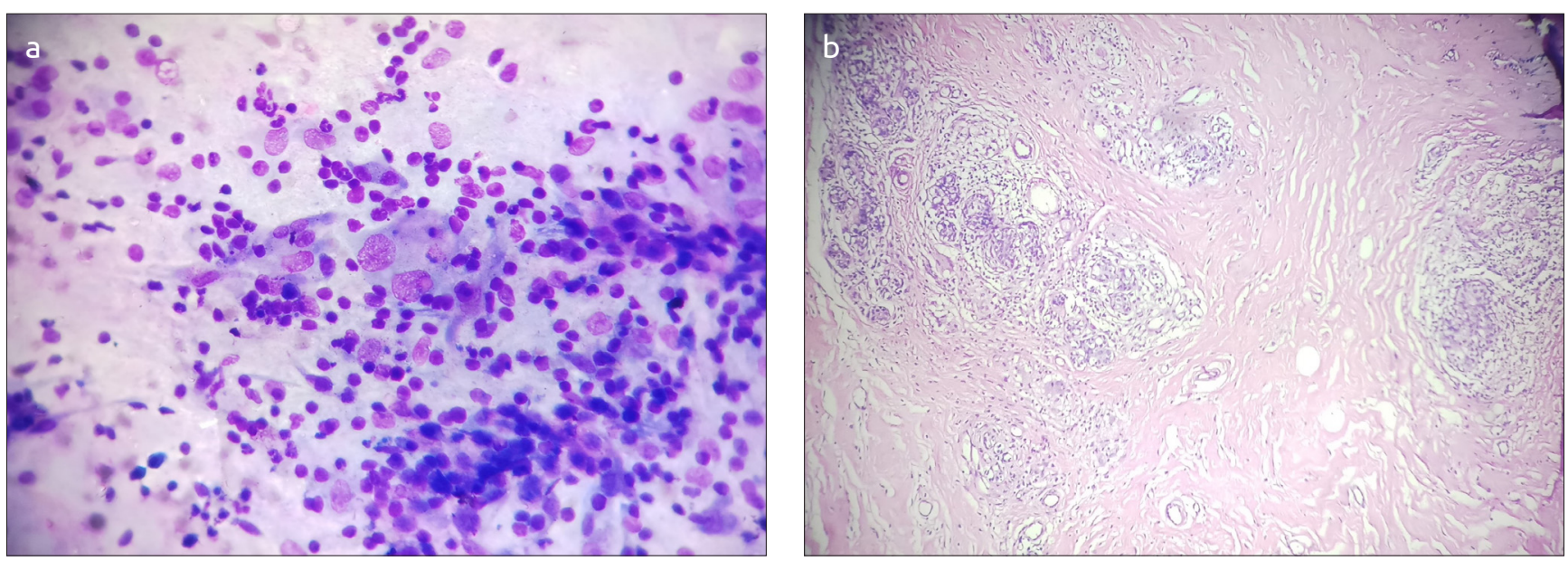

Figure 3. a, b. (a) Smears show lymphocytes on background and few atypical cells (Leishman stain x400). (b) Breast tissue show inflammatory cells and occasional epithelioid granuloma (Arrow) confined to breast lobules (Haematoxylin and Eosin x100)

tial number of cases $(\mathrm{n}=12)$ were evenly distributed in the remaining age groups (Table 3). Khanna et al. (14) observed TB mastitis in 15 - 58 years of age group while in our study oldest patient was of 70 years old. Though it is extremely rare in males, it is known to occur (14).

Three different clinical types such as nodular, sclerosing and disseminated have been identified in breast tuberculosis. The commonest is nodular variant (11). Similar observations were made in our study (Table 2). Ultrasonography and mammography lack specificity $(11,13)$. Though lactation makes the breast vulnerable to tuberculosis, only one patient in our study gave history of lactation. Similarly, other constitutional symptoms like fever, weight loss and night sweats did not aid in the definitive diagnosis of TB mastitis.

Though breast tuberculosis can be primary, it is believed that infection usually occur secondary to tubercular focus elsewhere in the body which may not be clinically or radiologically apparent. Similar observations were made in our study and other studies (22).

Out of 27 cases of TB mastitis, Group 2 cytomorphological features (Table 3) coupled with or without acid fast bacilli in FNA smears or AFB culture positivity established a definitive diagnosis of TB mastitis in 22 cases. In remaining five cases of GM, the diagnosis of Tb mastitis was aided by either AFB in FNA smears or culture or by histopathology. Detection of caseous necrosis in FNA smears depend on experience of the pathologist and is diagnostic of tuberculosis in developing countries like India. It is typically seen as acellular granular material with loss of cellular details (22). Out of 22 cases (Group 2 pattern) in which necrosis was seen, 10 cases showed caseous necrosis in our study.

Overall culture positivity was only $23 \%$ in our study. Possible reason can be inadequate material for culture.

IGLM is a rare chronic inflammatory disease of unknown aetiology (19). Autoimmune pathogenesis is proposed and accepted in many studies. It commonly occurs in patients with history of recent pregnancy and lactation (20). With increasing use of FNA as an initial investigative modality for breast lesions there is a need for an increased awareness of this disease entity. Cytomorphological features have been discussed in few foreign studies $(16-18,21)$. Ultrasonography and mammography lack specificity $(3,16-18)$. Usefulness and reliability of FNA is still debated. There is no commonly accepted treatment of
In our study, all the patients were in between 21 to 30 years with the mean age of 25 years while other studies observed higher mean age ranging from 33 to 35 years $(14,17,21)$. Three patients gave history of lactation within six months (Table 2).

Out of four cases of IGLM, three FNA smears showed Group 4 pattern and one case showed Group 3 pattern (Table 3). Gangopadhyay et al. (19) observed epithelioid granuloma, variable number of epithelioid histiocytes on the background and predominant polymorphonuclear inflammatory infiltrate. The Tse GMK (17) observed background epithelioid histiocytes as a dominant cytological feature in smears followed by epithelioid granulomas. Neutrophil was the dominant inflammatory infiltrate. Lymphocytes, plasma cells and giant cells were in variable numbers. The Seo Na HR (21) studied 24 patients of IGLM and only $25 \%$ patients were diagnosed on FNA, while remaining patients showed non-specific inflammatory findings or insufficient material in FNA smears. In our series, epithelioid granuloma, polymorphonuclear infiltrate were dominant features in cytology smears $(n=3)$. Variable number of lymphocytes, plasma cells and giant cells were seen. The remaining one case showed Group 3 pattern and she was a 25-year-old female and she complained of non-healing surgical wound and increase in size of the lesion. Possible reason for suppurative necrosis in FNA smears (Group 3) can be due to secondary bacterial infection. In all these cases, we were not able to demonstrate AFB or fungi in FNA smears and there was no clinical or radiological evidence of tuberculosis. Histological examination in all these cases showed inflammatory infiltrate confined to lobules. It mostly comprised of lymphocytes, plasma cells and occasional collection of epithelioid cells. There was no necrosis. AFB and fungal stains on tissues did not revealed AFB and fungi. Final diagnosis of IGLM was made in all four cases.

Remaining 2 cases in which FNA smears showed Group 2 pattern, both cases showed fatty necrosis on histological examination which evoked granulomatous reaction. ZN stain did not reveal AFB or fungi and the patient gave history of minor surgical intervention at the site three months back. To conclude, GM is a rare uncommon benign breast disease. There is a need to identify specific aetiology preoperatively for appropriate therapy. Tuberculosis is the most common cause of GM in developing countries like India. IGLM occur in younger age group as compared to tuberculous mastitis. Epithelioid granulomas with caseous necrosis with or without AFB in FNA smears and cul- 
ture is diagnostic of $\mathrm{Tb}$. Smears in which AFB or caseous necrosis is not detected histopathology provide definitive diagnosis, FNA smears showing epithelioid cells/ granulomas with predominant polymorphs without necrosis or AFB, a diagnosis of IGLM must be considered. Histopathological examination is essential for definitive diagnosis.

Ethics Committee Approval: Ethics committee approval was received for this study from the ethics committee of Dr D Y Patil Medical College and Hospital, Pimpri Pune.

Informed Consent: Written informed consent was obtained from patients who participated in this study.

\section{Peer-review: Externally peer-reviewed.}

Author Contributions: Concept - S.C.; Design - S.C., P.N.; Supervision S.C., A.R.; Resources - A.S., M.S.; Materials - S.C., M.S.; Data Collection and/or Processing - A.Ab., A.R.; Analysis and/or Interpretation - S.C., P.N.; Literature Search - A.R., M.S.; Writing Manuscript - S.C., P.N.; Critical Review - S.C., A.S.; Other - A.R., M.S.

Conflict of Interest: The authors have no conflicts of interest to declare.

Financial Disclosure: The authors declared that this study has received no financial support.

\section{References}

1. Gal-Gombos EC, Esserman LE, Odzer SL, Weisberg S, Wilson C, Poppiti RJ. Granulomatous mastitis: Diagnosis by ultrasound guided core biopsy. Breast J 2001; 7: 129-130. (PMID: 11328323) [CrossRef]

2. Ocal K, Dag A, Turkmenoglu O, Kara T, Seyit H, Konca K. Granulomatous mastitis: Clinical, pathological features and management. Breast J 2010; 2: 176-182. (PMID: 20030652) [CrossRef]

3. Gupta RK. Fine needle aspiration cytology of granulomatous mastitis. A study of 18 cases. Acta Cytologica 2010; 54: 138-141. (PMID: 20391968) [CrossRef]

4. Cakir B, Tunebilek N, Karkas HM, Unlu E, Ozyilmaz F. Granulomatous mastitis mimicking breast carcinoma. Breast J 2002; 8: 251-252. (PMID: 12100120) [CrossRef]

5. Chaiwun B, Settakorn J, Ya-In C, Wisedmongkol W, Rangdaeng S, Thorner P. Effectiveness of fine needle aspiration cytology of breast. Analysis of 2375 cases from northern Thailand. Diagn Cytopathol 2002; 26: 201-205. (PMID: 11892030) [CrossRef]

6. Nguansangiam S, Jesdapatarakul S, Tangijitgamol S. Accuracy of fine needle aspiration cytology from breast masses in Thailand. Asian Pac J Cancer Prev 2009; 10: 623-626.
7. Kessler E, Wolloch Y. Granulomatous mastitis. A lesion clinically simulating carcinoma. Am J Clin Pathol 1972; 58: 642-646. (PMID: 4674439) [CrossRef]

8. Jayaram G. Cytomorphology of tuberculous mastitis. Acta Cytol 1985; 29: 974-978.

9. Bani-Hani KE, Yaghan RJ, Matalka II, Santnawi NJ. Idiopathic granulomatous mastitis: time to avoid unnecessary mastectomies. Breast J 2004; 10: 318-322. (PMID: 15239790) [CrossRef]

10. Asoglu O, Ozmen V, Karanlik H, et al. Feasibility of surgical management in patients with granulomatous mastitis. Breast J 2005; 11: 108114. (PMID: 15730456) [CrossRef]

11. Shind SR, Chandavarkar RY, Deshmukh SP. Tuberculosis of the breast masquerading as carcinoma: A study of 100 patients. World J Surg 1995; 19: 379-381. (PMID: 7638992) [CrossRef]

12. Banerjee SN, Ananthakrishnan N, Mehta RB, Prakash S. Tuberculous mastitis: A continuing problem. World J Surg 1987; 11: 105-109. (PMID: 3811379) [CrossRef]

13. Hamit HF, Ragsdale TH. Mammary tuberculosis. J R Soc Med 1982; 75 : 764-765. [CrossRef]

14. Khanna R, Prasanna GV, Gupta P, Kumar M, Khanna S, Khanna AK. Mammary tuberculosis: Report on 52 cases. Postgrad Med J 2002; 78: 422-428. (PMID: 12151660) [CrossRef]

15. Vassilakos P. Tuberculosis of breast. Cytological findings with fine needle aspiration. Acta Cytol 1973; 17: 160-165.

16. Mudduwa LK, Nagahawatte Ade S. Diagnosis of tuberculous lymphadenitis: combining of cytomorphology, microbiology and molecular techniques - a study from Sri Lanka. Indian J Pathol Microbiol 2008; 51 : 195-197. (PMID: 18603679) [CrossRef]

17. Miliauskas JK, Pieterse AS, Williams RS. Granulomatous lobular mastitis. Aust N Z J Surg 1995; 65: 139-141. (PMID: 7857229) [CrossRef]

18. Akcan A, Akyildiz H, Deneme MA, Akgun H, Aritos Y. Granulomatous lobular mastitis: a complex diagnostic and therapeutic problem World J Surg 2006; 30: 1403-1409. (PMID: 16847715) [CrossRef]

19. Gangopadhyay M, De A, Chakrabarti I, Ray S, Giri A, Das R. Idiopathic granulomatous mastitis - utility of fine needle aspiration cytology (FNAC) in preventing unnecessary surgery. J Turk Ger Gynecol Assoc 2010; 11: 127-130. (PMID: 24591917) [CrossRef]

20. Tse GM, Poon CS, Law BK, Pang LM, Chu WC, Ma TK. Fine needle aspiration cytology of granulomatous mastitis. J Clin Pathol 2003; 56: 519-521. (PMID: 12835297) [CrossRef]

21. Roy S, Mondal SK, Amin R, Khan IS. Idiopathic Granulomatous Mastitis - Challenges of diagnosis and treatment. Medicine Today 2016; 28: 14-16. [CrossRef]

22. Seo Na HK, Young Na K, Yim HE, Kim TH, Kang DK, Oh Keun K, et al. Differential diagnosis in Idiopathic Granulomatous mastitis and tubercular mastitis. J Breast Cancer 2012; 15: 111-118. (PMID: 22493637) [CrossRef] 